\title{
AERODYNAMIC IMPROVEMENT OF AN AIRCRAFT GAS-TURBINE ENGINE FAN
}

Institute of Technical Mechanics

of the National Academy of Sciences of U kraine and the State Space Agency of U kraine

15 Leshko-Popel St., D nipro 49005, U kraine; e-mail: yukv@i.ua; zinevich7385@ gmail.com

\begin{abstract}
This work is concerned with the development of approaches to the aerodynamic improvement of axial-flow compressors for gas-turbine engines. The aim of this work is the aerodynamic improvement of an aircraft gasturbine engine two-stage fan by numerical simulation of 3D turbulent gas flows. The approach used in this study features: varying the spatial shape of the fan blades for the first- and the second-stage impeller by varying the profile angle along the blade height; formulating quality criteria as the mean integral values of the power characteristics of each impeller of the fan over the operating range of the air flow rate through the impeller; and searching for advisable values of the impeller blade parameters by scanning the independent variable range at points that form a uniformly distributed sequence of small length. The basic tool is a numerical method developed at the Institute of Technical Mechanics of the National Academy of Sciences of Ukraine and the State Space Agency of Ukraine, which simulates 3D turbulent gas flows using the complete averaged Navier-Stokes equations and a two-parameter turbulence model. It is shown that varying the profile angle along the blade height for the fan second-stage impeller allows one to increase the air compression ratio in the fan by about 2 percent throughout the operating range of the fan air flow rate without affecting the adiabatic efficiency of the fan. On the whole, by the example of the fan under study, the paper considers the assumption that the aerodynamic improvement of compressors at the initial stage can be made on an impeller by impeller basis. It is shown that in further analysis providing the gas-dynamic stability of the compressor should be accounted for. The results obtained are intended to be used in the aerodynamic improvement of multistage compressors for aircraft gas-turbine engines and various power plants.
\end{abstract}

Keywords aerodynamic improvement, fan, impeller, numerical simulation, power characteristics.

1. Matveev V. N., Baturin O. V., Popov G. M. Multistage compressor performances improvement by using optimization methods. Aerospace engineering and Technology. 2013. No. 8. Pp. 103-107. (in Russian).

2. Baturin O. V., Popov G. M., Goryachkin E. S., Smirnova Yu. D. Three-stage axial-flow compressor reprofiling using mathematical optimization methods. Trudy MAI. 2015. No. 82. Pp. 1-33. (in Russian).

3. Shelkovsky M. Yu. Aerodynamic improvement of axial ten-stage compressor of stationary GTE. Aerospace Engineering and Technology. 2014. No. 9. Pp. 27-32. (in Russian).

4. Schnoes M., Voß C., Nicke E. Design optimization of a multi-stage axial compressor using throughflow and a database of optimal airfoils. J. Glob. Power Propuls. Soc. 2018. V. 2. Pp. 516-528.

https://doi.org/10.22261/JGPPS.W5N91I

5. Jinxin Cheng, Zhaohui Dong, Shengfeng Zhao, Hang Xiang. Research on Aerodynamic Optimization Method of Multistage Axial Compressor under Multiple Working Conditions Based on Phased Parameterization Strategy. Mathematical Problems in Engineering. 2021. URL: https://www.hindawi.com/journals/mpe/2021/5518507/ (last accessed on April 26, 2021). 
6. Kvasha Yu. A. Calculation of the 3D turbulent flow in supersonic compressor stage blade channels (in Russian). Teh. Meh. 1999. No. 1. Pp. 913.

7. Kvasha Yu. A. Zinevych N. A. On the choice of computational grids in the numerical simulation of 3D turbulent flows in supersonic compressor stage impellers. Teh. Meh. 2013. No. 3. Pp.. 34-41. (in Russian).

8. Sobol I. M., Statnikov R. B. Choice of Optimum Parameters in Multicriteria Problems. Moscow: Nauka, 1981. 110 pp. (in Russian).

9. Nogin V. D. Pareto Set and Principle. St Petersburg: Publishing Association of Universities, 2020. 100 pp. (in Russian).

10. Kazandzhan P. K., Tikhonov N. D., Yanko A. K. Theory of Aircraft Engines. Theory of Blade Machines. Moscow: Mashinostroyeniye, 1983. 217 pp. (in Russian). 